\title{
Study to Determine the Prevalence of High Blood Pressure amongst Bankers Working in Abuja, the Federal Capital Territory, Nigeria
}

\author{
Article by Karthy christy Ebhohimen \\ Public Health, Texila American University, Nigeria \\ E-mail: osemudiamene@gmail.com
}

\section{Introduction}

Hypertension is one of the most important causes of the total disease burden in the world (LloydSherlock et al., 2014).

Non-communicable diseases, especially Coronary Artery Disease (CAD) including hypertension as a major risk factor accounts for almost $53 \%$ and $44 \%$ of deaths and disability adjusted life years (DALYs) (Mengistu, 2014).

Blood pressure is the single most useful test for identifying individuals with CAD (Barron et al., 2014).

CAD are nowadays increasingly seen in working people in age group of 35-64 years, in whom 35\% of CAD deaths are observable (Adeloye et al., 2015; Angaw, Dadi and Alene, 2015).

Hypertension is an increasingly important medical and public health issue worldwide (Ma et al., 2013; Chen et al., 2014).

Currently, the prevalence of hypertension in many developing countries, particularly in urban societies is said to be as high as those observed in developed countries (Addo, Smeeth and Leon, 2007; Guwatudde et al., 2015).

The burden of hypertension in Nigeria is high and still growing (Adeloye et al., 2015) and we still cannot say with certainty the exact burden because of lack of usable data(Ujunwa et al., 2013).

\section{Problem statement}

Ideal surveillance data for hypertension in Africa is lacking, nonetheless the available epidemiological data gives cause for concern (Gupta-Malhotra et al., 2015). In Nigeria, the prevalence of hypertension has been shown to be on the increase, based on secondary hospital data through a retrospective desk review.

A recent observational study (review of medical records) in some hospital in Abuja, Nigeria in August 2015 revealed that the prevalence of hypertension in urban males $35.6 \%$, rural males $53.3 \%$, urban females $25.7 \%$ and rural females $44.5 \%$.

\section{Aim of the study}

The overall aim of this study was to study the prevalence, determinants and risks associated with blood pressure categories based on combination of systolic and diastolic blood pressure, among bankers in Abuja, FCT Nigeria.

\section{Specific objectives of study}

\section{The objectives of this study are as follows:}

- To examine the prevalence, awareness, treatment, and control of HTN in bankers in FCT-AbujaNigeria.

- To identify professionally specific risk factors (lifestyle, diet) for HTN and cardiovascular disease (CVD) that can be targeted in future public health interventions.

- To determine possible risk factors for hypertension among bankers.

- To correlate between systolic and diastolic blood pressure and factors like age, sex, BMI and so on. 
DOI: $10.21522 /$ TIJPH.2013.05.04.Art012

ISSN: $2520-3134$

\section{Justification of study}

- Currently, in Nigeria, very few studies have evaluated the prevalence of hypertension. By investigating random samples from the population, an insight to the burden of the disease among bankers in Abuja, Nigeria can lead to the extrapolation of the disease burden in Nigeria. This study was carried out to determine the prevalence of hypertension among bankers in FCT, Abuja Nigeria. Using data from this study, the results could be inferred to other district within Nigeria.

- The study further evaluated the risk factors associated with hypertension. By having such data at hand, policy makers can design prevention or reduction strategies that are specific to a particular population. The study also provided an insight to how the bankers in Abuja, FCT Nigeria understood hypertension and its associated risk factors.

\section{Research questions}

- How does the profession like banking influence on the prevalence of Hypertension in Nigeria?

- Does the BMI of such Bankers correlate with their blood pressure values?

- What are the identified risk factors associated with blood pressure among bankers in Abuja, FCT Nigeria?

- Are there age and gender differences of the blood pressure among the studied bankers?

\section{Research hypotheses}

- $\mathrm{H}_{1}=$ Profession like banking influence on the prevalence of Hypertension in Nigeria

- $\mathrm{H}_{0}=$ Profession like banking do not influence on the prevalence of Hypertension in Nigeria

- $\mathrm{H} 1=\mathrm{BMI}$ correlate strongly positive with their blood pressure values

- $\mathrm{H} 0=$ BMI do not correlate strongly positive with their blood pressure values

- $\mathrm{H} 1=$ There are age and gender differences of the blood pressure among the studied bankers

- $\mathrm{H} 0=$ There are no age and gender differences of the blood pressure among the studied banker

\section{Prevalence of hypertension}

Hypertension has been associated with various factors whose prevalence varies in different populations due to differences in cultural, economic and social environments. (Manimunda et al., 2011; Ngui et al., 2011).

There are two (2) types of risk factors as classified; Modifiable and Non-modifiable. Under Modifiable we have; Body Weight, Sodium Chloride Intake, Alcohol Intake, Physical Inactivity, Psychosocial Stressors, Socio-Economic Status, Hormonal Contraceptives, Diet \& Smoking. While under Non-Modifiable we have Demographics \& Genetics.

\section{Knowledge on hypertension and its associated risk factors}

Recent studies have shown that with respect to health risk behaviors, many people are unaware of their own risk behavior and regard their behavior as more positive than it really is (Addo, Smeeth and Leon, 2007a; Domingos and Serra, 2011; Kibret and Mesfin, 2015).

This lack of awareness or misperception exists for behaviors in which the threshold between what is healthy and what is unhealthy is not very straightforward. For example, several studies have shown that misperception often occurs for behaviors like physical activity (Ronda et al, 2001), nutrition and sun bathing (Opie and Seedat, 2005).

In a study on physical activity among the Dutch general population it was found that of those who did not meet the physical activity guideline, $51 \%$ estimated their own physical activity as sufficient or high (Levy et al., 2009). For health risk behavior like smoking this phenomenon does not occur, since it is very clear that smoking is always unhealthy and people obviously know whether they smoke or not (Prochaska and Diclemente, 2003).

In a study carried out in Ashanti, West Africa the obesity and physical inactivity, were perceived as signs of prosperity and not as health risks (Opie and Seedat, 2005). In a study carried out in the Seychelles, over $96 \%$ of the participants knew that salt and obesity were associated with hypertension, and that hypertension was associated with CVD occurrence (Aubert, et al, 2000). 


\section{The pathophysiology of hypertension}

Hypertension is considered a serious problem because of the many complications it could possibly lead to if not diagnosed, monitored, and treated. One of the many serious complications hypertension could lead to is a cerebral hemorrhage or stroke. Untreated hypertension can eventually lead to high blood pressures rupturing a cerebral artery, thus bringing damage to the brain (Basu and Millett, 2013). There are many different types of hypertension. The most common one is called primary or essential hypertension. Primary hypertension can arise in two ways. If there is excessive vasoconstriction of the small arterioles, there can be high diastolic blood pressure. High systolic blood pressure can come as an effect of high peripheral resistance; to compensate for the resistance, the heart must pump harder. Because of the extra effort the heart has to make and because of the added pressure on the vessels, there are many effects on the heart, blood vessels, and kidneys (Gupta-Malhotra et al., 2015)

Left ventricular hypertrophy can result from the heart working so hard. The muscles in the heart become enlarged. This does not cause immediate heart problems, but eventually the heart can descend into cardiac failure or congestive heart failure. Many of the symptoms include bloating, irregular pulse, fatigue, and swelling in the feet, ankles, and abdomen. Besides left ventricular hypertrophy, a patient could also develop hypertrophic cardiomyopathy, a similar condition. Another cardiac side-effect would be ischemic heart disease. This is when a heart attack occurs because the heart is not getting enough blood, and thus, oxygen. Symptoms involved include fatigue, irregular pulse, dizziness, and chest pain (Pereira et al., 2009; Nwankwo et al., 2013).

Besides heart problems, essential hypertension can lead to mild to severe vascular effects. A person can develop arteriosclerosis - the high, continuous pressure leads to arteriole injury. The injuries lead to degenerative changes and the lumen becomes narrowed. If the wall has reached a breaking point, it can turn necrotic and even burst (Yang et al., 2015)

Blood pressure, like height and weight, is a continuous biological variable with no cut-off point separating normotension from hypertension. The continuous relationship between the level of blood pressure and cardiovascular risk makes any numerical definition and classification of hypertension somewhat arbitrary. Therefore, a definition of hypertension is usually taken as that level of arterial blood pressure associated with doubling of long-term cardiovascular risk (Mengistu, 2014).

\section{Hypertension among bankers}

Very few studies have looked at the nature and assessment of hypertension among bankers around the world and it is almost non-existent in Nigeria. However, Salaudeen et al., (2014), have indicated the prevalence of hypertension among bankers at $30.4 \%$ and prehypertension at $34.5 \%$ in a cross-sectional study of 1493 bank employees of Surat city of India which was conducted during August, 2004 to September, 2005. The researchers also reported that out of 455 found as hypertensive, $258(56.70 \%)$ were not having any symptoms at the time of examination. Prevalence was high among persons with age 50 years and above (48.5\%); among male (32.5\%) as compared to female (23.1\%); among employees having small family size; among separated or divorced person (40.0\%). Prevalence of hypertension increased with seniority of the official position of bank employee with highest prevalence among managers (45.9\%). To study the magnitude of the problem of hypertension among bank employees, the effect of body mass index (BMI) and body fat distribution as measured by waist-to-hip ratio (WHR) on prevalence of hypertension among bank employees of Surat city and the effect of different types of food habits and exercise on the prevalence of hypertension, Awosan et al., (2013), undertook a cross sectional study carried out from August, 2004 to September, 2005. A total of 1493 bank employees were studied (1177 males and 316 females). A pre-tested semi structured questionnaire was used, which collected information on demographic characteristics and risk factors for hypertension. Hypertension was defined on the basis of 7th report of Joint National Committee (JNC). Data on lifestyle habits (smoking and physical activity), body height, waist and hip circumferences and blood pressure measured using standardized protocols. The overall prevalence of hypertension was found to be $30.4 \%(455 / 1493)$. Among 455(30.4\%) hypertensive, only 197(43\%) were aware about their hypertensive status, and 139(70.5\%) were on regular treatment. $71(51 \%)$ were having controlled hypertension among the employees who were on regular treatment. Prevalence of hypertension was higher $40.1 \%$ (149) among alcohol consumer than non- drinker $27.2 \%$ (306). This study also found the 
prevalence of hypertension to be significantly higher among employees who were not having any healthy habit like walking, jogging, exercise.

In a recent study to assess the prevalence and risk factors of hypertension among bank employees, Katyal and Katyal, (2013), undertook a cross-sectional study of 128 male and 64 female bank employees from 12 nationalized banks in urban Puducherry, India. Blood pressure was measured and classified according to the Joint National Committee (JNC) VII criteria. Data on risk factors of hypertension, including consumption of extra salt while dining, eating high-salt food, junk food, servings of fruits and vegetables, smoking, alcohol use, physical activity, and body mass index, were obtained for each participant using a standard questionnaire. Stress level was assessed by Cohen's Perceived Stress scale. The prevalence of hypertension and pre-hypertension was found to be $44.3 \%$ and $41.1 \%$ respectively. Out of 85 participants with hypertension, 47 (55\%) was known cases and 38 (45\%) were newly diagnosed. The study also found that living in the 4th or 6th decade life, consumption of extra salt, and physical activity $\geq 2$ hours per day were associated with hypertension among bank employees.

\section{Stress, work schedules and hypertension}

Job - related stress has become a very important risk factor for hypertension. There is evidence of a positive association between work hours and hypertension in working populations. Work-related risk factor for hypertension identified in the past few years is work hours. In a quantitative study, Zeng et al., (2013), investigated work hours and self-reported hypertension among the working population in the state of California, USA. The study used data from the Public Use File of the 2001California Health Interview Survey. The finding indicated a positive association between hours worked per week and likelihood of having self-reported hypertension. Compared with those working between 11 and 39 hours per week, individuals working 40 hours per week were $14 \%$ more likely to report hypertension, those who worked between 41 and 50 hours per week were 17\% more likely to report hypertension, and those who worked 51 hours per week were $29 \%$ more likely to report hypertension after controlling for various potentially confounding variables, including demographic and biological risk factors and socioeconomic status.

Very limited data exist on the duration of work or number of hours an employee spends at work and hypertension. However, in a study to find out the effect of exposure to occupational noise and shift working on blood pressure, (Yang et al., 2015), collected demographic, medical and occupational data from a group of 331 workers of Yazd in Iran. The participants were put into four groups according to work shift and noise exposure severity, from non-noise exposed day time workers (Group1) to noise exposed shift workers (Group 4). Finally, systolic and diastolic blood pressure levels were compared among these four groups. The findings showed a significant difference between average systolic and diastolic BP and hypertension (HTN) frequency across the groups. The highest rate of HTN and mean systolic and diastolic BP were observed among shift workers who were exposed to noise higher than permissible limit. Also the results of logistic regression analysis revealed a significant relationship between simultaneous exposures to noise more than the permitted limit and shift work with HTN and also that shift working and simultaneous exposure to noise have an additive effect on occurrence of Hypertension.

\section{Prevention of hypertension}

International guidelines, such as those of the WHO Expert Committee on Hypertension Control (WHO, 2014) and the National technical Education Program (FMOH, 2010), have stressed the importance of primary prevention of hypertension. The goal of such an intervention would include preventing the blood pressure rise observed with ageing, lowering overall blood pressure levels in the population and addressing other modifiable risk factors in an effort to decrease cardiovascular morbidity and mortality. A population-based programme to slightly lower overall blood pressure levels and prevent the rise of blood pressure associated with ageing would have an effect on cardiovascular disease equal to or greater than that of treating patients with established hypertension. Epidemiological and clinical studies uniformly indicate that obesity, sedentary lifestyle and intake of salt and alcohol are all associated with increased risk of developing hypertension. In order to decrease the incidence of hypertension in the general population the following lifestyle modifications are necessary: 
- weight control

- $\quad$ increased physical activity

- $\quad$ limiting dietary sodium to $\leq \square 2.4$ per day (equivalent to $6 \mathrm{~g}$ of sodium chloride)

- $\quad$ abstention from alcohol

- Increased dietary potassium.

Adopting the DASH eating plan, which is a diet rich in fruits, vegetables and low-fat dairy products and low in saturated and total fat and cholesterol, is more important than just altering individual micronutrients such as sodium. Pre-hypertensive are at higher risk of developing hypertension and cardiovascular disease than those with normal blood pressure and are therefore excellent targets for primary prevention. Individuals with a family history of hypertension and those with a predisposition to develop obesity or diabetes are also excellent candidates for programs to reduce weight, salt intake, alcohol use and improve dietary habits while increasing exercise. These recommendations help promote health in all persons but are especially important in those with other risk factors for hypertensionassociated conditions, such as coronary artery disease.

Studies concerning awareness, treatment and control of high blood pressure as well as the continued prevalence of hypertension suggest that primary prevention is not being effectively practiced. Barriers to prevention include:

- $\quad$ cultural norms;

- $\quad$ insufficient attention to health education by health care practitioners;

- lack of reimbursement for health education services;

- $\quad$ lack of access to places to engage in physical activity;

- $\quad$ larger servings of food in restaurants;

- lack of availability of healthy food choices in many schools, worksites and restaurants;

- $\quad$ lack of exercise programs in schools;

- $\quad$ large amounts of sodium added to foods by the food industry and restaurants;

- The higher cost of food products that are low in sodium and calories.

Overcoming the barriers will require a multipronged approach directed not only to high-risk populations but also to communities, schools, worksites and the food industry. The recent recommendations that the food industry reduce sodium in the food supply by $50 \%$ over the next decade is the type of approach that, if implemented, would reduce high blood pressure in the population. An equally important area of concern is the need for improvement in provider and patient communication.

The lifestyle changes used to help prevent hypertension are very difficult for many people, especially those at highest risk who often must give up many long-term habits. Recommendations for dietary and activity changes by a provider have little chance of being followed if their importance and potential benefits are not communicated to the patient. Such communication is dependent on the provider's confidence in his/her ability to teach patients the necessary skills to follow recommendations and the amount of time available for preventive services. Health care organizations may help remedy this problem by providing training, personnel and support to address patient education and counselling.

\section{Research methodology}

\section{Study area}

This study was carried out among commercial bank workers in Abuja, the federal capital territory; the territory is located just north of the confluence of the Niger River and Benue River.

\section{Study population}

The study population is made up of all the professional bank staff.

\section{Sample size estimation}

This is made up of all the professional bank workers in the selected banks' main branch and a branch of each of them. A minimum sample size was calculated based on a population (of bank workers) $<10,000$ with prevalence of hypertension of $20 \%$ from a previous study.

The sample size was estimated using Fisher's formula (Fisher 1991).

The formula for sample size calculation using; $\mathrm{N}=\mathrm{Z}^{2} \mathrm{PQ} / \mathrm{d}^{2}$, Where: $\mathrm{N}=$ Minimum sample size. 
DOI: $10.21522 /$ TIJPH.2013.05.04.Art012

ISSN: $2520-3134$

$\mathrm{Z}=$ Constant, standard normal deviation (1.96 for $95 \%$ confidence interval), $\mathrm{P}=20 \%$

$\mathrm{Q}=1-\mathrm{P}$

$\mathrm{d}=$ Acceptable margin of error $\mathrm{Z}=1.96, \mathrm{P}=0.2, \mathrm{Q}=0.8$ and $\mathrm{d}=0.05$

$\mathrm{N}=(1.96)^{2} \times 0.2(1-0.2) /(0.05)^{2}$

$\mathrm{N}=394$ was the minimal sample size calculated.

But four hundred individuals will be used in the actual study to minimize errors.

\section{Sampling technique}

Seven banks (two thirds) were randomly selected by balloting from the eleven banks. One branch from each of the selected seven banks was randomly selected to add to the main branch of the seven banks giving a total of fourteen branches that were studied.

\section{Inclusion/exclusion criteria}

Only professional banking staff members were included in the study. Those who had less than one year experience at the bank were excluded from the study. Professional staff members that consented verbally were studied.

\section{Study design}

This was a cross-sectional descriptive survey. A pre-tested semi-structured questionnaire which assessed their knowledge of hypertension, risk factors, adherence to management as well as demographic attributes was self-administered to the respondents.

Knowledge of hypertension was based on a set of standard questions covering its definition, risk factors, treatment and complications. The blood pressure was measured); weight and height of the respondents were checked and recorded in $\mathrm{mmHg}, \mathrm{Kg}$ and meters respectively.

\section{Ethical consideration}

Verbal and written consent was also obtained from management and staff of the banks selected.

\section{Limitation of the study}

The findings from this study are not applicable to the general population as the bank workers are not representative of the various aspects of the population; in age, sex distribution, occupation, educational level, social status and location of residence.

\section{Statistical analysis}

The Statistical Package for Social Sciences (SPSS) version 20 statistical software was used for data analysis.

For continuous variables, mean values and standard deviations were calculated and the means compared using the independent samples $t$ test.

Locality and gender differences in prevalence rates were compared with Pearson Chi-Square.

Pearson correlation coefficient was used to analyse the relationship between blood pressure, age and anthropometric data, $\mathrm{p}$-values below 0.05 were considered statistically significant, while those above that were considered statistically insignificant.

\section{Results}

\section{Characteristics of the study population}

There were four hundred (400) participants in the study, males of 193(48.3) was slightly less than females 207(51.7). The mean age of the males was 32.79 \pm 4.34 and females were 29.10 \pm 5.92 . The mean weight, BMI, SBP and DBP were significantly slightly higher in males than in females $(p<0.05)$ as shown in table 4.1. T- test statistics showed that there was a significant difference between the mean age, weight, height, BMI, SBP and DBP values between males and females ( $\mathrm{p}<0.05)$ 
Table 1. Characteristics of the study population by gender

\begin{tabular}{lllll}
\hline Variables & $\begin{array}{l}\text { Male } \\
\mathbf{n = 1 9 3} \mathbf{( 4 8 . 3 )} \\
\text { Mean } \pm \text { SD }\end{array}$ & $\begin{array}{l}\text { Female } \\
\mathbf{n = 2 0 7}(\mathbf{5 1 . 7}) \\
\text { Mean } \pm \text { SD }\end{array}$ & $\begin{array}{l}\text { t-test } \\
\text { value }\end{array}$ & p-value \\
\hline AGE(YEARS) & $32.79 \pm 4.34$ & $29.10 \pm 5.92$ & -9.11 & $<0.0001$ \\
\hline WEIGHT(KG) & $77.72 \pm 7.56$ & $68.55 \pm 9.40$ & -13.83 & $<0.0001$ \\
\hline HEIGHT(M) & $1.81 \pm 0.15$ & $1.65 \pm 0.09$ & -23.92 & $<0.0001$ \\
\hline BMI(KG/M $\left.{ }^{2}\right)$ & $23.97 \pm 2.95$ & $25.16 \pm 3.06$ & 5.56 & 0.001 \\
\hline SBP $($ MM/HG) & $135.74 \pm 19.19$ & $125.32 \pm 14.17$ & -10.81 & $<0.0001$ \\
\hline DBP (MM/HG) & $88.41 \pm 10.99$ & $80.74 \pm 9.92$ & -11.34 & $<0.0001$ \\
\hline
\end{tabular}

Keys:

n=number, $\mathbf{S D}=$ Standard Deviation

$\mathrm{SDP}=$ Systolic blood pressure

DBP=Diastolic blood pressure

Figure 1, 2 \& 3 shows the mean value of SBP, DBP among gender, age group and local government area

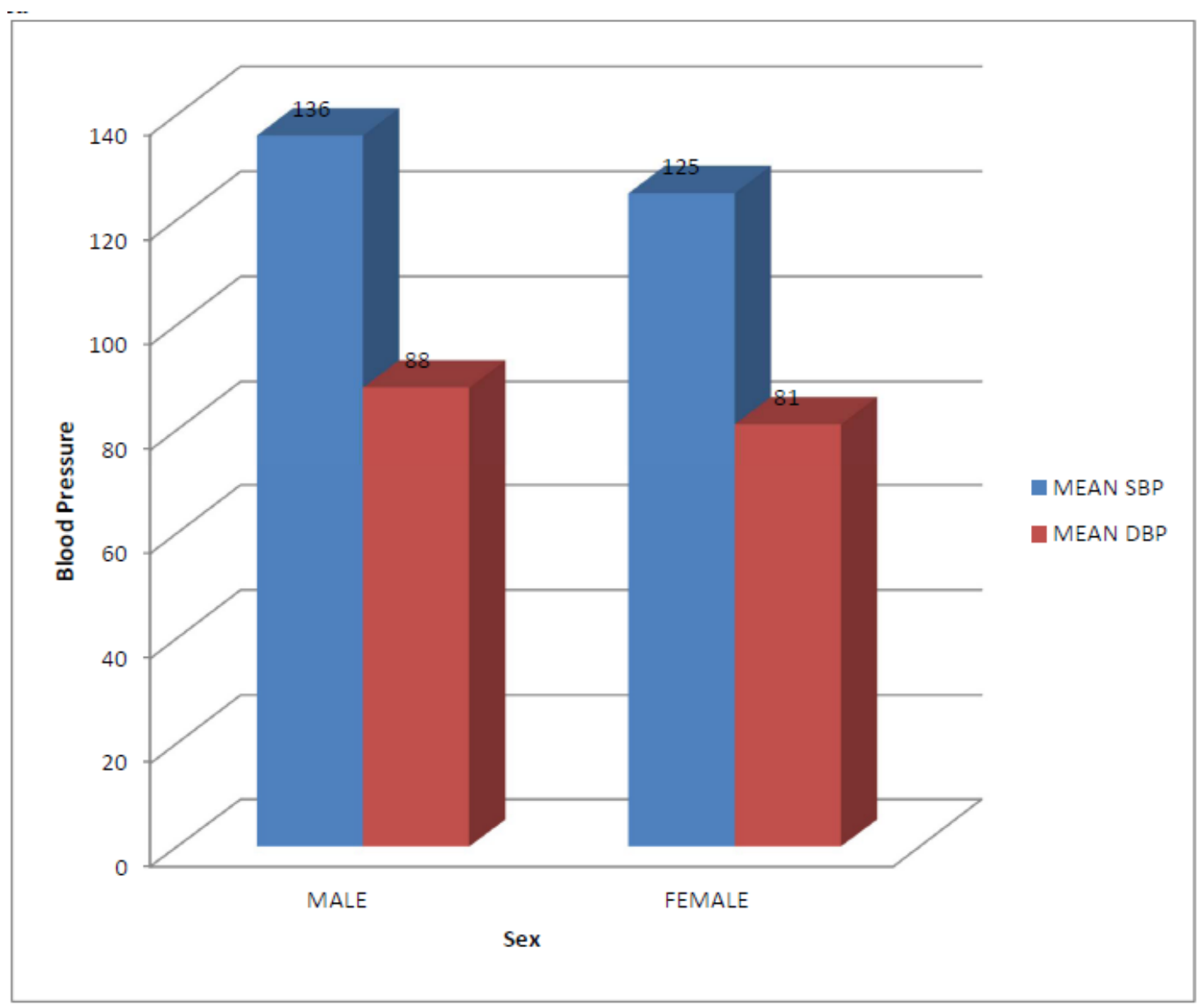

Figure 1. Relationship of systolic and diastolic blood pressure with sex

SDP $=$ Systolic blood pressure

$\mathrm{DBP}=$ Diastolic blood pressure 
DOI: 10.21522/TIJPH.2013.05.04.Art012

ISSN: $2520-3134$

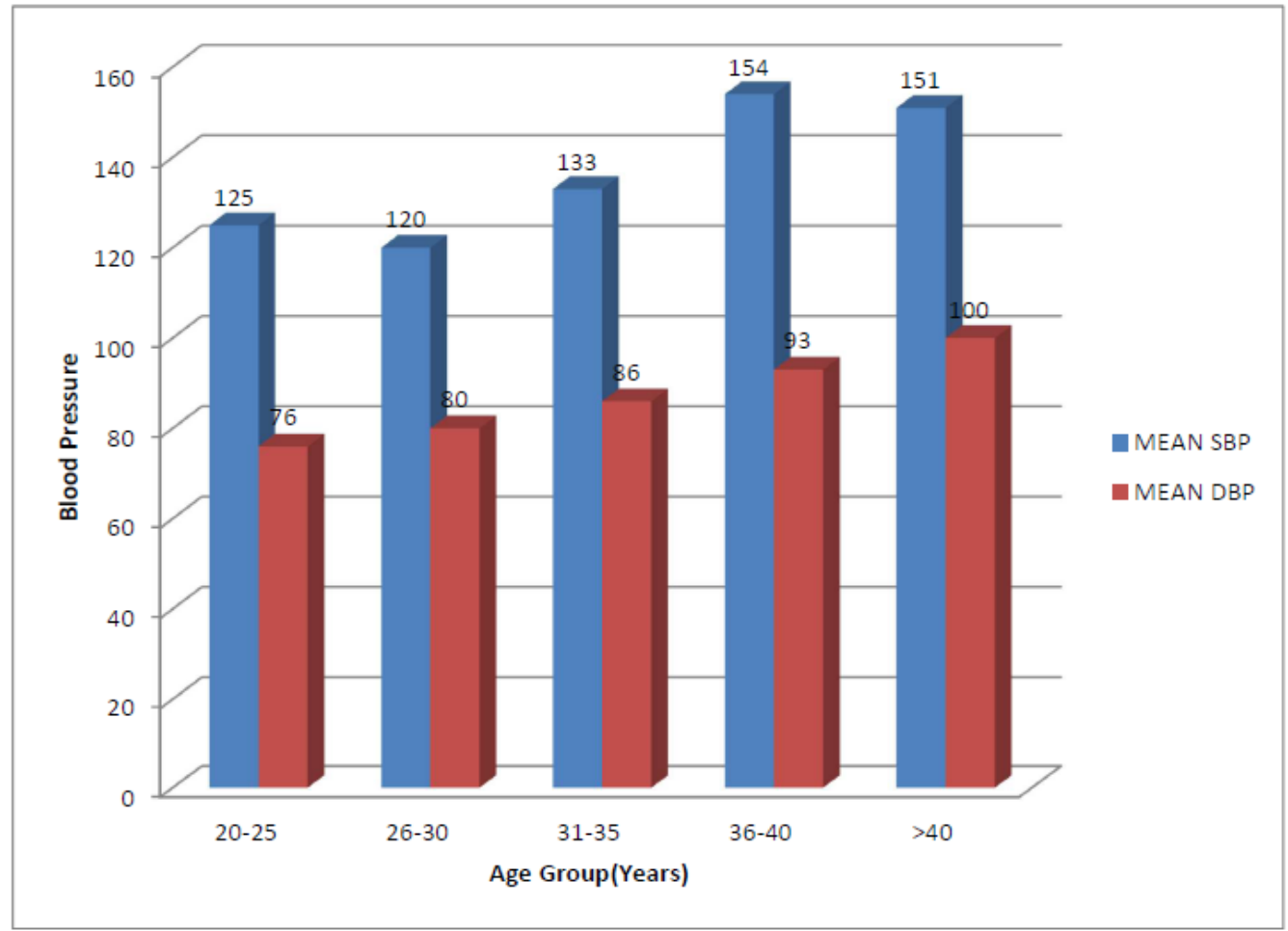

Figure 2. Relationship of systolic and diastolic blood pressure with age group

SDP=Systolic blood pressure

$\mathrm{DBP}=$ Diastolic blood pressure

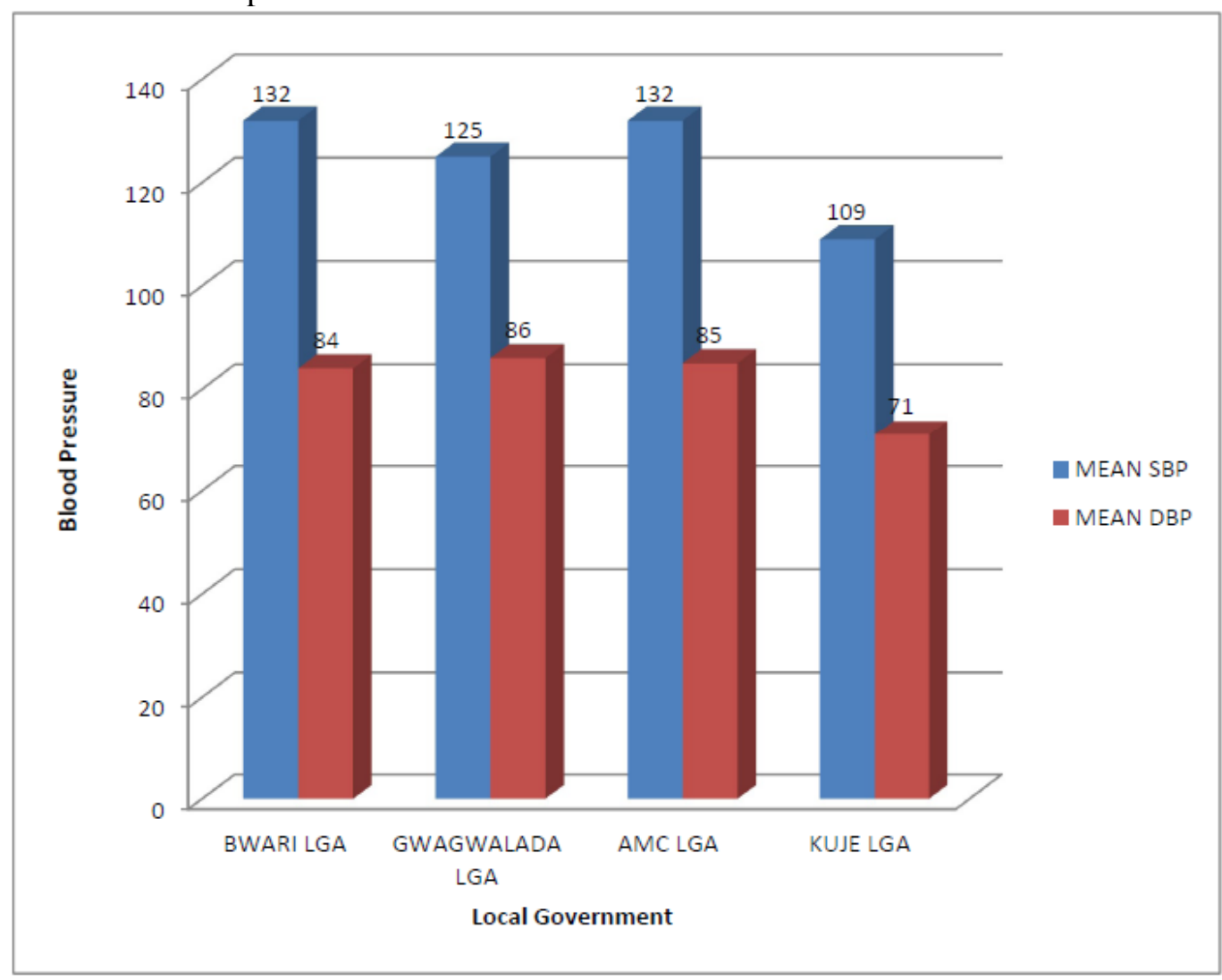

Figure 3. Relationship of systolic and diastolic blood pressure with local government

$\mathrm{SDP}=$ Systolic blood pressure

DBP=Diastolic blood pressure 


\section{Prevalence of hypertension}

There were $37.3 \%$ (149/400) hypertensive cases in this study with $62.7 \%(102 / 149)$ be males and $37.3 \%$ (47/149) been females with the prevalence increasing with age, age group 31-35 of $45.6 \%$ had the highest hypertension occurrences.

\section{OVER LL PREVALENCE OF HYPERTENSION IN THE STUDY BASED ON SBP/DBP OF 140/90}

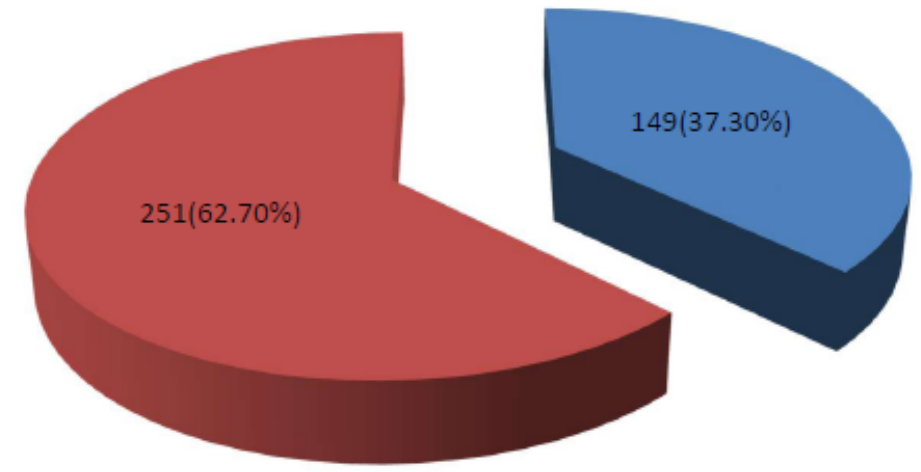

Figure 4. Prevalence of hypertension on the study based on SBP/DBP of 140/90

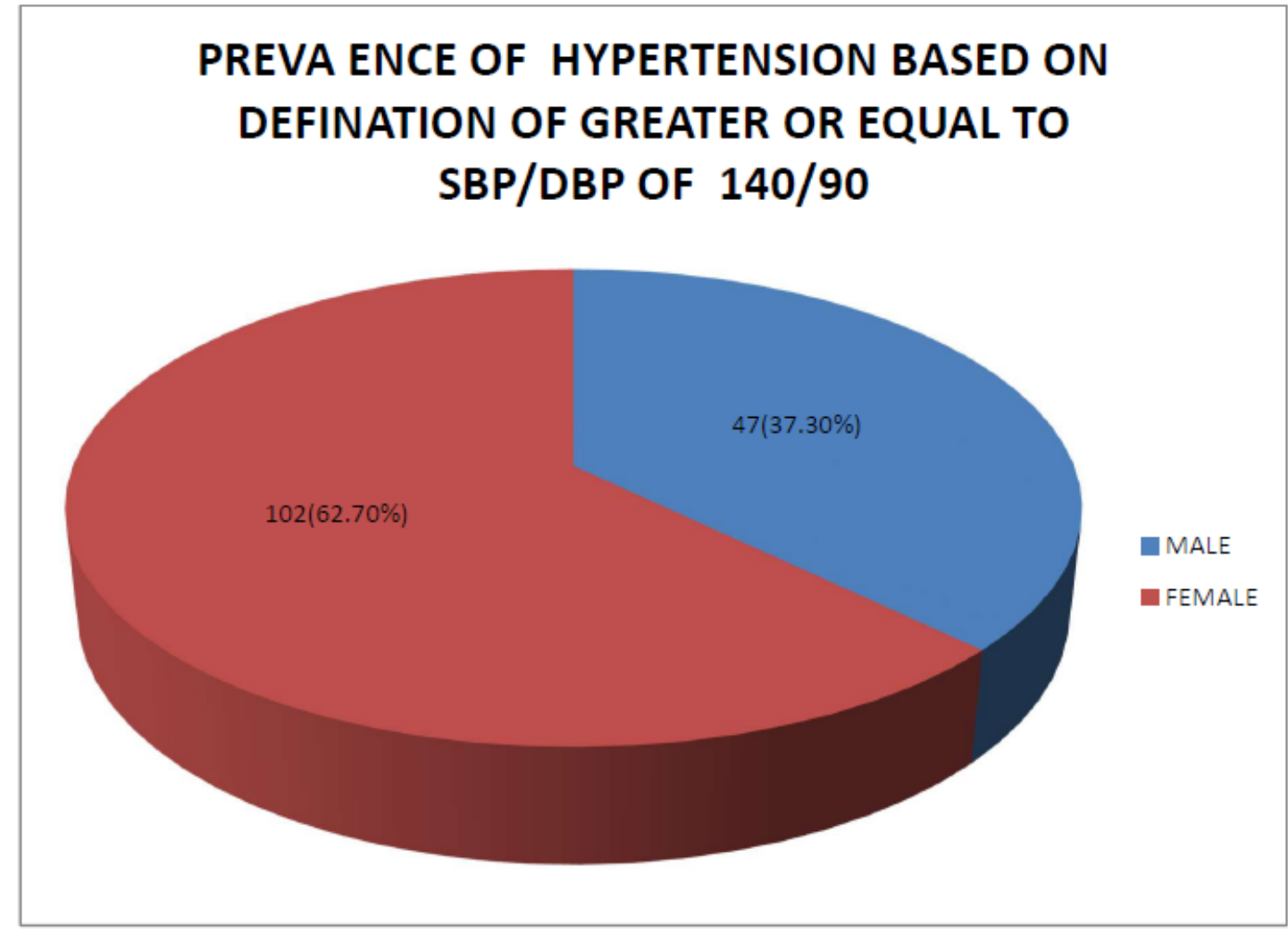

Figure 5. Prevalence of hypertension by sex 


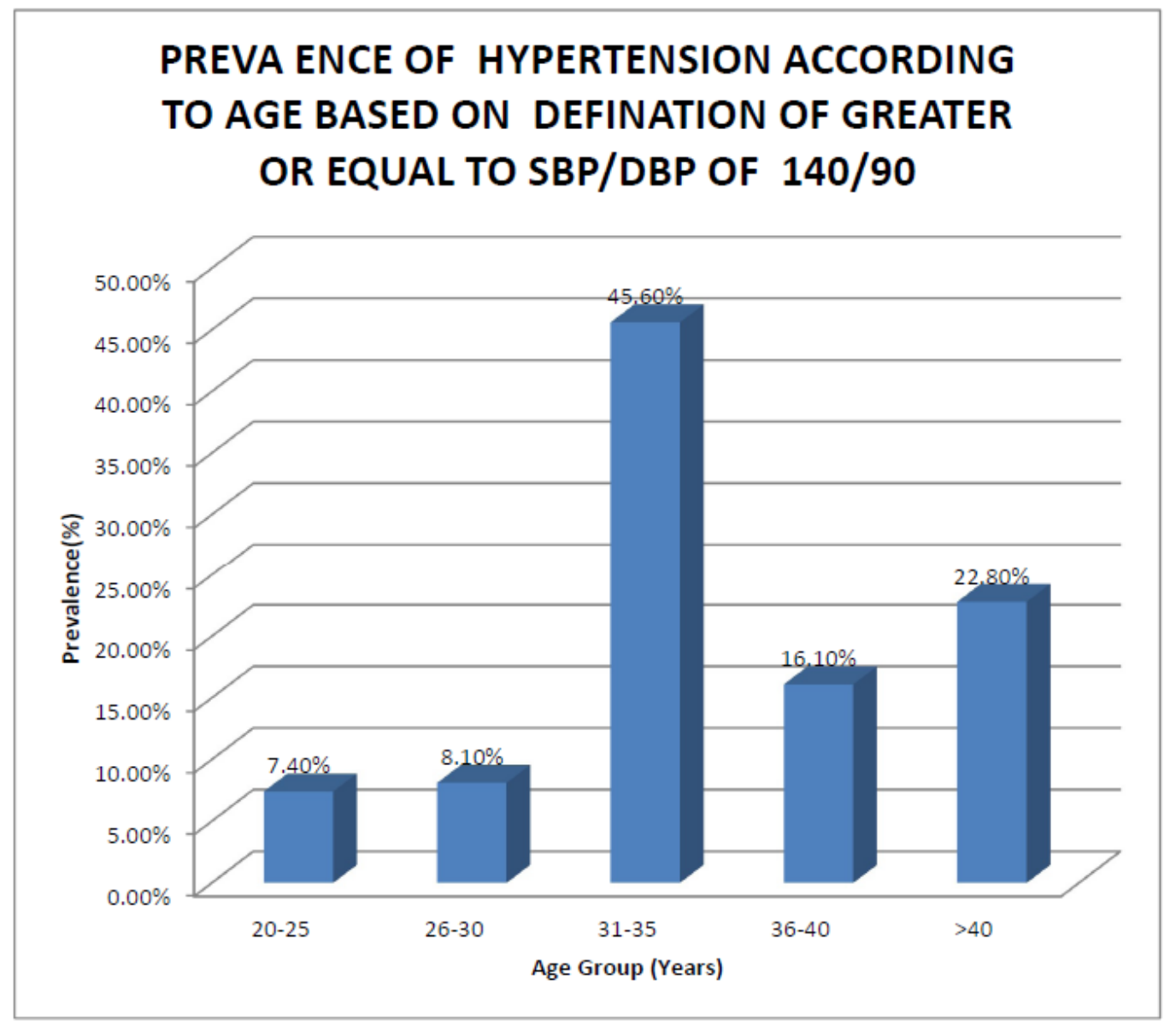

Figure 6. Prevalence of hypertension by age group

\section{Comparison of DBP and SBP with anthropometric parameters}

Pearson correlation analysis revealed that SBP AND DBP correlated strongly positively with age weight, BMI, while SBP do not correlated with height but DBP correlated weakly positively with it as shown in table 4.2

Table 2. Correlation between blood pressure, age and anthropometric variables

\begin{tabular}{cll}
\hline Variables & $\begin{array}{l}\text { SBP } \\
\text { r(p-value })\end{array}$ & $\begin{array}{l}\text { DBP } \\
\text { r(p-value }\end{array}$ \\
\hline AGE & 0.571 & 0.628( \\
(YEARS) & $(0.0000)$ & $0.0000)$ \\
\hline WEIGHT & 0.366 & 0.469 \\
(KG) & $(0.00000)$ & $(0.0000)$ \\
\hline HEIGHT & 0.078 & 0.186 \\
(M) & $(0.121)$ & $(0.005)$ \\
\hline BMI & 0.296 & 0.276 \\
KG/M $\left.^{2}\right)$ & $(0.0001)$ & $(0.0000)$ \\
\hline
\end{tabular}

Keys; BMI=Body Mass Index, r=correlation coefficient $\mathrm{SDP}=$ Systolic blood pressure

$\mathrm{DBP}=$ Diastolic blood pressure

\section{Comparison of mean value of SBP and DBP according BMI classification}

Analysis showed that the mean value of SBP and DBP of normal weight individuals were statistically significant different $(\mathrm{p}<0.05)$ from those of overweight, underweight, class one obesity and class two obesity as shown in table 3 
Texila International Journal of Public Health Volume 5, Issue 4, Dec 2017

Table 3. Anova Table of mean value of SBP and DBP according To BMI classification

\begin{tabular}{|c|c|c|c|c|c|c|c|}
\hline \multirow[t]{2}{*}{ Variable } & \multicolumn{5}{|c|}{ BMI Classifcation } & \multicolumn{2}{|l|}{ Statistics } \\
\hline & $\begin{array}{l}\text { CL1OB } \\
\text { Mean } \pm S D \\
n=11\end{array}$ & $\begin{array}{l}\text { CL2OB } \\
\text { Mean } \pm \text { SD } \\
n=12\end{array}$ & $\begin{array}{l}\text { NW } \\
\text { Mean } \pm \text { SD } \\
n=250\end{array}$ & $\begin{array}{l}\text { UNW } \\
\text { Mean } \pm \text { SD } \\
n=14\end{array}$ & $\begin{array}{l}\text { OVW } \\
\text { Mean } \pm \text { SD } \\
113\end{array}$ & F-VALUE & $\begin{array}{l}\text { P- } \\
\text { VALUE }\end{array}$ \\
\hline SBP & $\begin{array}{l}143.09 \pm 1 . \\
30\end{array}$ & $\begin{array}{l}150.24 \pm 1 \\
74\end{array}$ & $\begin{array}{l}125.50 \pm 16 . \\
65\end{array}$ & $\begin{array}{l}140.54 \pm 5.2 \\
3\end{array}$ & $\begin{array}{l}137.13 \pm 17 \\
70\end{array}$ & 17.29 & $<0.00001$ \\
\hline DBP & $\begin{array}{l}99.24 \pm 1.3 \\
0\end{array}$ & $\begin{array}{l}110.12 \pm 1 \\
43\end{array}$ & $\begin{array}{l}81.81 \pm 10.9 \\
5\end{array}$ & $90.26 \pm 5.23$ & $86.61 \pm 8.90$ & 26.51 & $<0.001$ \\
\hline
\end{tabular}

\section{Keys:}

$\mathrm{CL} 10 \mathrm{~B}=$ Class 1 Obesity, $\mathrm{CL2OB}=\mathrm{Class}$ 2Obesity, NW=Normal weight, UNW=Under Weight, OVW=Over Weight, $\mathrm{n}=$ number, $\mathrm{SD}=$ Standard Deviation.

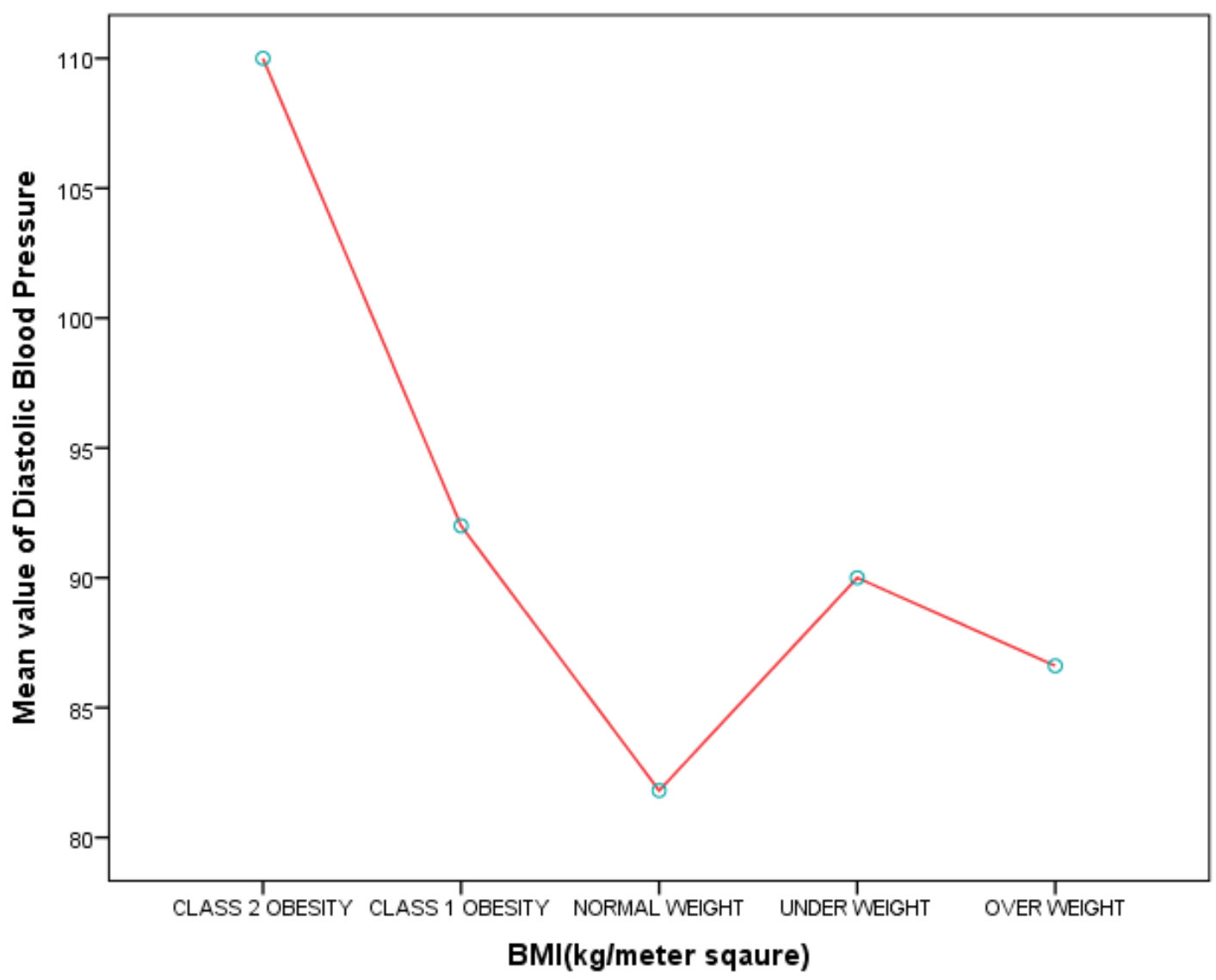


DOI: $10.21522 /$ TIJPH.2013.05.04.Art012

ISSN: $2520-3134$

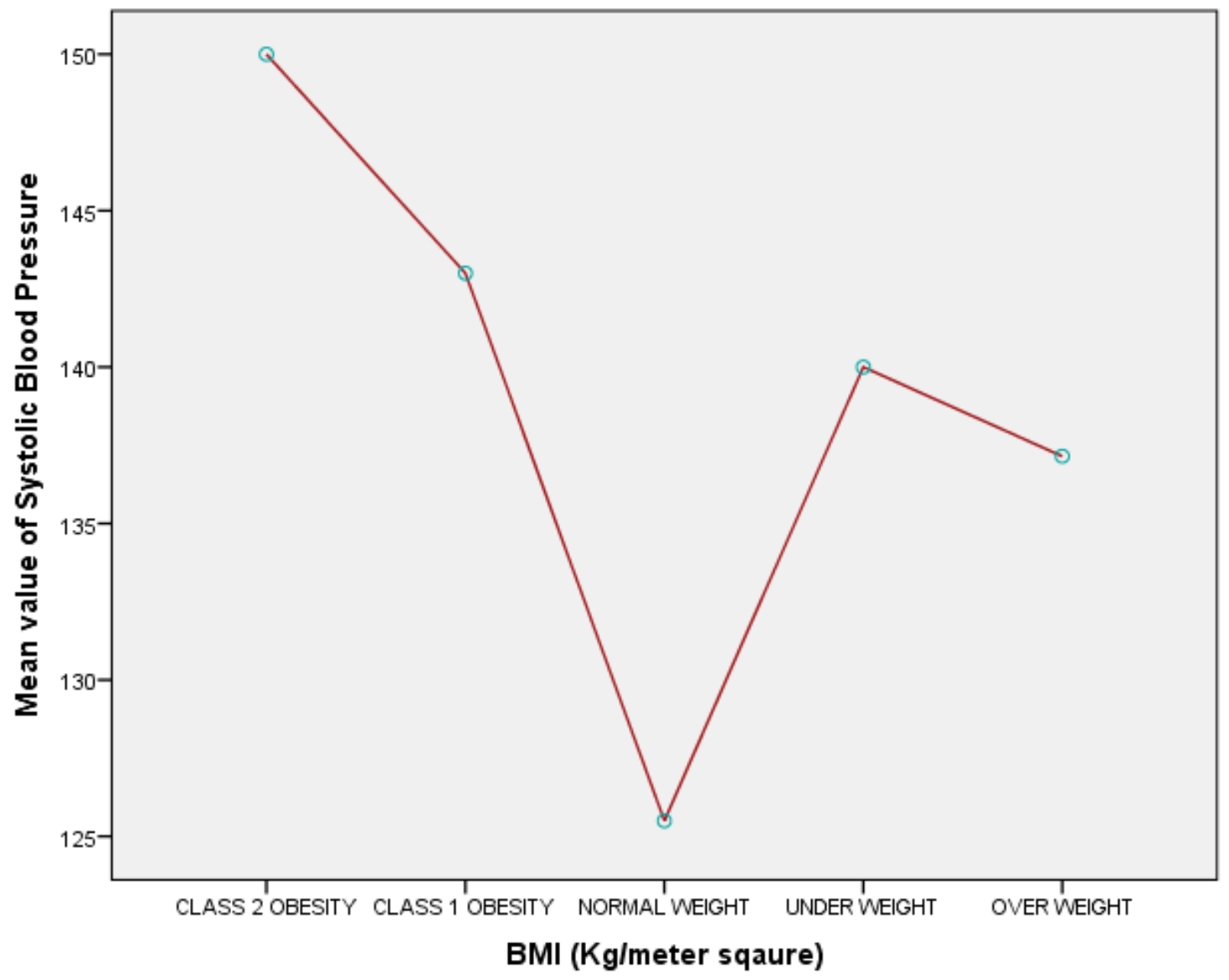

\section{Comparison of mean value of BMI according to classification of blood pressure}

It was observed that the mean value of normal blood pressure individuals were statistically significantly different from those of grade one hypertension, grade two hypertension and isolated systolic hypertension with $\mathrm{p}<0.05$, while it was statistically insignificant from those of pre-hypertension and optimal blood pressure $(\mathrm{p}>0.05)$ 


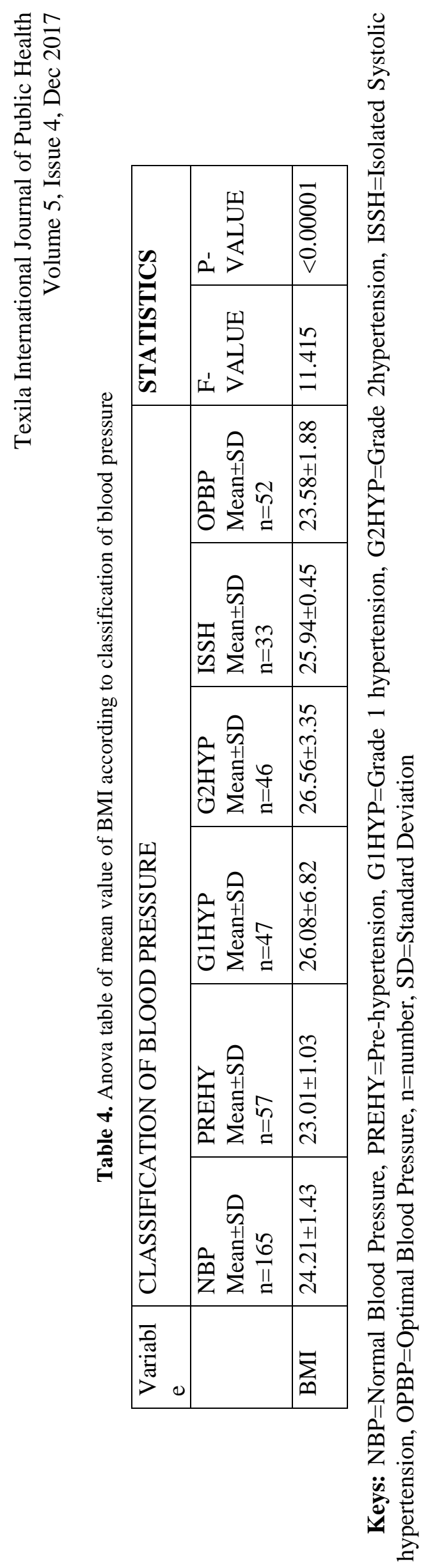


DOI: $10.21522 /$ TIJPH.2013.05.04.Art012

ISSN: $2520-3134$

\section{Risk factor assessment in relation to hypertension}

The analysis of the risk factors for been hypertensive using binary logistic regression model, showed that irregular blood pressure check, high cholesterol , smoking, staying around smokers, not having health goal and regular alcohol consumption were identified as possible risk factors with $\mathrm{p}<0.05$ in this study.

\section{Discussion}

There has being a lot of studies on blood pressure among Nigerian. Hypertension is prevalent among Nigerians and it has been associated with high level of morbidity and mortality and bank workers are not exempted from this assertion. Their job specification can be stressful and can be associated with elevated blood pressure. A total of 400 bank workers were studied with slightly more females $(51.7 \%)$ compared to the males (48.3\%). This is slightly different from the observation among bank workers in Owerri, Nigeria (Ogah, 2012; Awosan et al., 2013). Also Abuja is an urban city with increased exposure to sources and exchange of information by people, advancement in science and technology and easy access to information via mass media and the internet. However, in Ilorin, more than half the bank workers had a good knowledge of the associated risk factors for hypertension (Abougalambou and Abougalambou, 2013).

In our study the overall prevalence of hypertension was $37.30 \%$, the prevalence of hypertension in this study was similar to the findings in among bankers Ilorin (34.4\%) (Abougalambou and Abougalambou, 2013) and the report of (Cooper et al., 1997), where it was found to be $32.8 \%$ among bankers in Enugu Nigeria and 32.6\% for blacks in the United States, but it was less than those from report from study among bankers in Benin City (17.7\%) and Sokoto $(22.9 \%)$ and national prevalence which was above $7 \%$. This may be attributable to the fact that their job specification which is demanding and competitive and other study showed that Hypertension was more prevalent in the urban area with a rate of $32.7 \%$ than in the rural area where a prevalence rate of $12.9 \%$ (Addo, Smeeth and Leon, 2007b; Midha, 2013; Bosu, 2015). It could also be attributed to the fact that the study area is an urban setting. This study has also demonstrated a rising trend in the prevalence of hypertension since 1997 as asserted by (Cooper et al., 1997). This increasing trend has been noted across the globe with prevalence rates of 28.3\% noted in Accra Ghana by (Addo et al., 2012).

Also the prevalence was higher among the male bank workers (62.7\%) compared to the females with $37.30 \%$. In general no clear pattern of association between hypertension and gender has emerged. Our findings correlate with other studies conducted in Ibadan, Nsukka, Enugu and South South region of Nigeria. In the international study of hypertension in blacks carried out by (Cooper et al., 1997), the prevalence of hypertension was higher in men than women in Nigeria and Cameroon. However, a study carried out more recently in Kumasi Ghana revealed higher prevalence in women than men (Duedu $e t$ al., 2014; Li et al., 2015)

Mufunda et al., (2006), reported a higher prevalence of hypertension in women than men in 1996 and this they attributed to hyperinsulinemia.

In our study there seem to be a linear relationship between blood pressure and age, it was revealed that the prevalence of hypertension increased with age from $7.4 \%$ in the $20-25$ age group $45.6 \%$ in the 31-35 age group. There was a drop in the 36-40 age group and then arise in age group $>40$ age group. This may be accounted for by the few number of participants in this age group and the age of the banker workers which usually fall within 20-50 age ranges. Linear association between blood pressure and age have however been widely reported (Dalal et al., 2011; Rafael V. Picon et al., 2012; Tailakh et al., 2014).

In our study, it was found that bankers from the city center had higher SBP and DBP compared to those away from city. This can be due to sedentary lifestyle, changes in dietary habits in the form of high fat in diet as seen among urban dwellers. They hold large business, earn a lot of money and are considered to have a high socio-economic status, this finding agreed with findings in India were urban dwellers where more pose to hypertension than rural dwellers and another study also reported that there seem to be hypertension in relation to social economic status of individual, the higher the social economic status, the higher they are pose to hypertension, and it was linked to dietary state, which most 
time contained high fat content, fried food and soon (Thaweboon et al., 2008; Rafael V. Picon et al., 2012; Roberie and Elliott, 2012).

Some of the risk factors for hypertension are age and obesity measured by BMI in this study. Others include heavy alcohol consumption and smoking. Age, BMI and all correlated with hypertension with obesity class two being the strongest correlation with SBP and DBP followed by BMI. Other studies have also reported that BMI is positively and significantly associated with blood pressures across populations in diverse geographical settings (Levy et al., 2009; Abougalambou and Abougalambou, 2013; Ganesh, Naresh and Bammigatti, 2014). This shows that there is a direct relationship between obesity and hypertension. Other lifestyle modifications thought to be effective in management of hypertension such as exercise, and weight reduction observed to be low among the general bankers population termed to be very low because of their job specification and schedules. Other risk factors of cardiovascular disease found among the bank workers in this study were alcohol consumption, obesity and smoking(Ortiz Marrón et al., 2011; Addo et al., 2012; Catalá-López, Sanfélix-Gimeno and GarcíaTorres, 2012; Momin, Desai and Kavishwar, 2012; Abougalambou and Abougalambou, 2013; S. van de Vijver et al., 2013b; Ranasinghe et al., 2015).

\section{Conclusion and recommendations}

- The bank workers in Abuja Federal capital territory have high prevalence of hypertension with $37.30 \%$, with male subjects having higher hypertension prevalence against their female counterparts.

- Regular alcohol intake, obesity, smoking were the commonest risk factors among others observed.

- Continuous health education on chronic non communicable diseases such as hypertension is advocated while regular annual medical check-up should continue to be encouraged for those who are not diagnosed hypertensive.

- While the hypertensive bankers must adhere to prescribed medications as well as engage in lifestyle adjustments where necessary to avoid the risk of developing

\section{References}

[1]. Abougalambou, S. S. I. and Abougalambou, A. S. (2013) 'A study evaluating prevalence of hypertension and risk factors affecting on blood pressure control among type 2 diabetes patients attending teaching hospital in Malaysia.', Diabetes \& metabolic syndrome, 7(2), pp. 83-6. doi: 10.1016/j.dsx.2013.02.019.

[2]. Addo, J., Agyemang, C., Smeeth, L., de-Graft Aikins, a, Edusei, a K. and Ogedegbe, O. (2012) 'A review of population-based studies on hypertension in Ghana.' Ghana Medical Journal, 46(June), pp. 4-11. doi: 10.4314/gmj.v46i2.

[3]. Addo, J., Smeeth, L. and Leon, D. A. (2007a) 'Hypertension in sub-Saharan Africa: A systematic review', Hypertension, 50(6), pp. 1012-1018. doi: 10.1161/HYPERTENSIONAHA.107.093336.

[4]. Addo, J., Smeeth, L. and Leon, D. A. (2007b) 'Hypertension in sub-Saharan Africa: A systematic review', Hypertension, 50(6), pp. 1012-1018. doi: 10.1161/HYPERTENSIONAHA.107.093336.

[5]. Adeloye, D., Basquill, C., Aderemi, A. V, Thompson, J. Y. and Obi, F. a (2015) 'An estimate of the prevalence of hypertension in Nigeria: a systematic review and meta-analysis.', Journal of hypertension, 33(2), pp. 230-42. doi: 10.1097/HJH.0000000000000413.

[6]. Akinlua, J. T., Meakin, R., Umar, A. M. and Freemantle, N. (2015) 'Current prevalence pattern of hypertension in Nigeria: A systematic review’, PLoS ONE, 10(10). doi: 10.1371/journal.pone.0140021.

[7]. Angaw, K., Dadi, A. F. and Alene, K. A. (2015) 'Prevalence of hypertension among federal ministry civil servants in Addis Ababa, Ethiopia: a call for a workplace-screening program.' BMC cardiovascular disorders, 15, p. 76. doi: 10.1186/s12872-015-0062-9.

[8]. Awosan, K. J., Ibrahim, M. T. O., Sabir A A and Ejimodu, P. (2013) 'Awareness and prevalence of risk factors of coronary heart disease among teachers and bankers in Sokoto, Nigeria', Journal of Medicine and Medical Sciences, 4(9), pp. 335-342. doi: 10.14303/jmms.2013.116.

[9]. Baral, S., Beyrer, C., Muessig, K., Poteat, T., Wirtz, A. L., Decker, M. R., Sherman, S. G. and Kerrigan, D. (2012) 'Burden of HIV among female sex workers in low-income and middle-income countries: A systematic 
DOI: $10.21522 /$ TIJPH.2013.05.04.Art012

ISSN: $2520-3134$

review and meta-analysis', The Lancet Infectious Diseases, 12(7), pp. 538-549. doi: 10.1016/S14733099(12)70066-X.

[10]. Barron, S., Balanda, K., Hughes, J. and Fahy, L. (2014) 'National and subnational hypertension prevalence estimates for the Republic of Ireland: better outcome and risk factor data are needed to produce better prevalence estimates.' BMC public health, 14(1), p. 24. doi: 10.1186/1471-2458-14-24.

[11]. Basu, S. and Millett, C. (2013) 'Social epidemiology of hypertension in middle-income countries: Determinants of prevalence, diagnosis, treatment, and control in the WHO SAGE study', Hypertension, 62(1), pp. 18-26. doi: 10.1161/HYPERTENSIONAHA.113.01374.

[12]. Bosu, W. K. (2015) 'the prevalence, awareness, and control of hypertension among workers in West Africa: A systematic review', Global Health Action. doi: 10.3402/gha.v8.26227.

[13]. Calhoun, D. A., Booth, J. N., Oparil, S., Irvin, M. R., Shimbo, D., Lackland, D. T., Howard, G., Safford, M. M. and Muntner, P. (2014) 'Refractory hypertension: determination of prevalence, risk factors, and comorbidities in a large, population-based cohort.' Hypertension, 63(3), pp. 451-8. doi: 10.1161/HYPERTENSIONAHA.113.02026.

[14]. Catalá-López, F., Sanfélix-Gimeno, G. and García-Torres, C. E. Al (2012) 'Control of arterial hypertension in Spain: a systematic review and meta-analysis of 76 epidemiological studies on 341632 participants.' J Hypertens, 30(1), pp. 168-76. doi: 10.1097/HJH.0b013e32834d30ec.

[15]. Chen, X., Li, L., Zhou, T. and Li, Z. (2014) 'Prevalence of hypertension in rural areas of China: A metaanalysis of published studies', PLoS ONE, 9(12). doi: 10.1371/journal.pone.0115462.

[16]. Chifamba, J., Chakanyuka, K. E., Longo-Mbenza, B., Mahachi, C. B. and Mufunda, J. (2012) 'Comparison of exercise-induced hypertension in low birth weight and normal birth weight young black adults in zimbabwe', High Blood Pressure and Cardiovascular Prevention, 19(3), pp. 123-127. doi: 10.2165/11632150-00000000000000 .

[17]. Colosia, A. D., Palencia, R. and Khan, S. (2013) 'Prevalence of hypertension and obesity in patients with type 2 diabetes mellitus in observational studies: a systematic literature review.' Diabetes, metabolic syndrome and obesity : targets and therapy, 6, pp. 327-38. doi: 10.2147/DMSO.S51325.

[18]. Cooper, R., Rotimi, C., Ataman, S., McGee, D., Osotimehin, B., Kadiri, S., Muna, W., Kingue, S., Fraser, H., Forrester, T., Bennett, F. and Wilks, R. (1997) 'The prevalence of hypertension in seven populations of West African origin', American Journal of Public Health, 87(2), pp. 160-168. doi: 10.2105/AJPH.87.2.160.

[19]. Coronado-Castellote, L. and Jim??Nez-Soriano, Y. (2013) 'Clinical and microbiological diagnosis of oral candidiasis', Journal of Clinical and Experimental Dentistry, 5(5), pp. 279-286. doi: 10.4317/jced.51242.

[20]. Crim, M. T., Yoon, S. S., Ortiz, E., Wall, H. K., Schober, S., Gillespie, C., Sorlie, P., Keenan, N., Labarthe, D. and Hong, Y. (2012) 'National surveillance definitions for hypertension prevalence and control among adults', Circulation: Cardiovascular Quality and Outcomes, 5(3), pp. 343-351. doi: 10.1161/CIRCOUTCOMES.111.963439.

[21]. Dalal, S., Beunza, J. J., Volmink, J., Adebamowo, C., Bajunirwe, F., Njelekela, M., Mozaffarian, D., Fawzi, W., Willett, W., Adami, H. O. and Holmes, M. D. (2011) 'Non-communicable diseases in sub-Saharan Africa: What we know now', International Journal of Epidemiology, 40(4), pp. 885-901. doi: 10.1093/ije/dyr050.

[22]. Domingos, F. and Serra, A. (2011) 'Nephrolithiasis is associated with an increased prevalence of cardiovascular disease.' Nephrology, dialysis, transplantation : official publication of the European Dialysis and Transplant Association - European Renal Association, 26(3), pp. 864-8. doi: 10.1093/ndt/gfq501.

[23]. Duedu, K. O., Yarnie, E. A., Tetteh-Quarcoo, P. B., Attah, S. K., Donkor, E. S. and Ayeh-Kumi, P. F. (2014) 'A comparative survey of the prevalence of human parasites found in fresh vegetables sold in supermarkets and open-aired markets in Accra, Ghana', BMC Research Notes, 7(1), p. 836. doi: 10.1186/1756-0500-7-836.

[24]. Fekadu, S., Taye, K., Teshome, W. and Asnake, S. (2013) 'Prevalence of parasitic infections in HIV-positive patients in southern Ethiopia: A cross-sectional study', Journal of Infection in Developing Countries, 7(11), pp. 868-872. doi: 10.3855/jidc.2906.

[25]. FMOH (2010) National HIV Sero-prevalence Sentinel Survey: Technical report, Nigeria Federal Ministry of Health, Department of Public Health National AIDS/STI Control Programme. Available at: http://www.nigeriaaids.org/documents/2010_National HIV Sero Prevalence Sentinel Survey.pdf.

[26]. Ganesh, K. S., Naresh, A. G. V and Bammigatti, C. (2014) 'Prevalence and risk factors of hypertension among male police personnel in urban Puducherry, India', Kathmandu University Medical Journal, 12(48), pp. $242-246$. 
[27]. Ganesh Kumar, S. and Deivanai Sundaram, N. (2014) 'Prevalence and risk factors of hypertension among bank employees in urban Puducherry, India', International Journal of Occupational and Environmental Medicine, 5(2), pp. 94-100. doi: 10.4103/0972-6748.144938.

[28]. Gupta-Malhotra, M., Banker, A., Shete, S., Hashmi, S. S., Tyson, J. E., Barratt, M. S., Hecht, J. T., Milewicz, D. M. and Boerwinkle, E. (2015) 'Essential hypertension vs. secondary hypertension among children', American Journal of Hypertension, 28(1), pp. 73-80. doi: 10.1093/ajh/hpu083.

[29]. Guwatudde, D., Nankya-Mutyoba, J., Kalyesubula, R., Laurence, C., Adebamowo, C., Ajayi, I., Bajunirwe, F., Njelekela, M., Chiwanga, F. S., Reid, T., Volmink, J., Adami, H.-O., Holmes, M. D. and Dalal, S. (2015) 'the burden of hypertension in sub-Saharan Africa: a four-country cross sectional study', BMC Public Health, 15, p. 1211. doi: 10.1186/s12889-015-2546-z.

[30]. Hasumi, T. and Jacobsen, K. H. (2012) 'Hypertension in South African adults: results of a nationwide survey.' Journal of hypertension, 30(11), pp. 2098-104. doi: 10.1097/HJH.0b013e328357c018.

[31]. Judd, E. and Calhoun, D. A. (2014) 'apparent and true resistant hypertension: Definition, prevalence and outcomes', Journal of human hypertension, 28(8), pp. 463-468. doi: 10.1038/jhh.2013.140.

[32]. Kadiri, S., Walker, O., Salako, B. and Akinkugbe, O. (1999) 'Blood pressure, hypertension and correlates in urbanised workers in Ibadan, Nigeria: a revisit', Journal of Human Hypertension, 13, pp. 23-27. doi: 10.1038/sj.jhh.1000722.

[33]. Katyal, S. and Katyal, R. (2013) 'Prevalence of Occupational Stress among Bankers', International Journal of Humanities and Social Science Invention ISSN (Online, 2(4), pp. 2319-7722.

[34]. Kearney, P. M., Whelton, M., Reynolds, K., Whelton, P. K. and He, J. (2004a) 'Worldwide prevalence of hypertension', Journal of Hypertension, 22(1), pp. 11-19. doi: 10.1097/00004872-200401000-00003.

[35]. Kearney, P. M., Whelton, M., Reynolds, K., Whelton, P. K. and He, J. (2004b) 'Worldwide prevalence of hypertension: a systematic review.' Journal of hypertension, 22(1), pp. 11-9. doi: 10.1097/01.hjh.0000098149.7095679.

[36]. Kibret, K. T. and Mesfin, Y. M. (2015) 'Prevalence of hypertension in Ethiopia: A systematic meta-analysis', Public Health Reviews. doi: 10.1186/s40985-015-0014-z.

[37]. Kishore, J., Gupta, N., Kohli, C. and Kumar, N. (2016) 'Prevalence of Hypertension and Determination of Its Risk Factors in Rural Delhi', International Journal of Hypertension, 2016. doi: 10.1155/2016/7962595.

[38]. Levy, D., Ehret, G. B., Rice, K., Verwoert, G. C., Launer, L. J., Dehghan, A., Glazer, N. L., Morrison, A. C., Johnson, A. D., Aspelund, T., Aulchenko, Y., Lumley, T., Köttgen, A., Vasan, R. S., Rivadeneira, F., Eiriksdottir, G., Guo, X., Arking, D. E., Mitchell, G. F., Mattace-Raso, F. U. S., Smith, A. V, Taylor, K., Scharpf, R. B., Hwang, S.-J., Sijbrands, E. J. G., Bis, J., Harris, T. B., Ganesh, S. K., O’Donnell, C. J., Hofman, A., Rotter, J. I., Coresh, J., Benjamin, E. J., Uitterlinden, A. G., Heiss, G., Fox, C. S., Witteman, J. C. M., Boerwinkle, E., Wang, T. J., Gudnason, V., Larson, M. G., Chakravarti, A., Psaty, B. M. and van Duijn, C. M. (2009) 'Genomewide association study of blood pressure and hypertension.', Nature genetics, 41(6), pp. 677-87. doi: 10.1038/ng.384.

[39]. Li, S., Zhu, J., Zhang, W., Chen, Y., Zhang, K., Popescu, L. M., Ma, X., Bond Lau, W., Rong, R., Yu, X., Wang, B., Li, Y., Xiao, C., Zhang, M., Wang, S., Yu, L., Chen, A. F., Yang, X. and Cai, J. (2011) 'Signature microRNA expression profile of essential hypertension and its novel link to human cytomegalovirus infection', Circulation, 124(2), pp. 175-184. doi: 10.1161/CIRCULATIONAHA.110.012237.

[40]. Li, Z., Li, Y., Chen, L., Chen, P. and Hu, Y. (2015) 'Prevalence of Depression in Patients with Hypertension: A Systematic Review and Meta-Analysis.', Medicine, 94(31), pp. 1-6. doi: 10.1097/MD.0000000000001317.

[41]. Lloyd-Sherlock, P., Beard, J., Minicuci, N., Ebrahim, S. and Chatterji, S. (2014) 'Hypertension among older adults in low- and middle-income countries: prevalence, awareness and control', International Journal of Epidemiology, 43(1), pp. 116-128. doi: 10.1093/ije/dyt215.

[42]. Ma, Y.-Q., Mei, W.-H., Yin, P., Yang, X.-H., Rastegar, S. K. and Yan, J.-D. (2013) 'Prevalence of hypertension in Chinese cities: a meta-analysis of published studies.' PloS one, 8(3), p. e58302. doi: 10.1371/journal.pone.0058302.

[43]. Manimunda, S. P., Sugunan, A. P., Benegal, V., Balakrishna, N., Rao, M. V. and Pesala, K. S. (2011) 'Association of hypertension with risk factors \& hypertension related behaviour among the aboriginal Nicobarese tribe living in Car Nicobar Island, India', Indian Journal of Medical Research, 133(3), pp. 287-293. 
DOI: $10.21522 /$ TIJPH.2013.05.04.Art012

ISSN: $2520-3134$

[44]. Mengistu, M. D. (2014) 'Pattern of blood pressure distribution and prevalence of hypertension and prehypertension among adults in Northern Ethiopia: disclosing the hidden burden.' BMC cardiovascular disorders, 14(1), p. 33. doi: 10.1186/1471-2261-14-33.

[45]. Meshram, I. I., Arlappa, N., Balkrishna, N., Rao, K. M., Laxmaiah, a and Brahmam, G. N. V (2012) 'Prevalence of hypertension, its correlates and awareness among adult tribal population of Kerala state, India.' Journal of Postgraduate Medicine, 58(4), pp. 255-261. doi: 10.4103/0022-3859.105444.

[46]. Midha, T. (2013) 'Prevalence of hypertension in India: A meta-analysis', World Journal of Meta-Analysis, 1(2), p. 83. doi: 10.13105/wjma.v1.i2.83.

[47]. Missaye, A., Dagnew, M., Alemu, A. and Alemu, A. (2013) 'Prevalence of intestinal parasites and associated risk factors among HIV/AIDS patients with pre-ART and on-ART attending dessie hospital ART clinic, Northeast Ethiopia.', AIDS research and therapy, 10(1), p. 7. doi: 10.1186/1742-6405-10-7.

[48]. Momin, M. H., Desai, V. K. and Kavishwar, A. B. (2012) 'Study of socio-demographic factors affecting prevalence of hypertension among bank employees of Surat City.', Indian journal of public health, 56(1), pp. 448. doi: 10.4103/0019-557X.96970.

[49]. Mufunda, J., Mebrahtu, G., Usman, a, Nyarango, P., Kosia, a, Ghebrat, Y., Ogbamariam, a, Masjuan, M. and Gebremichael, a (2006) 'the prevalence of hypertension and its relationship with obesity: results from a national blood pressure survey in Eritrea.' Journal of human hypertension, 20(1), pp. 59-65. doi: 10.1038/sj.jhh.1001924.

[50]. Musinguzi, G. and Nuwaha, F. (2013) 'Prevalence, Awareness and Control of Hypertension in Uganda', PLoS ONE, 8(4). doi: 10.1371/journal.pone.0062236.

[51]. National Population Commission Npc Nigeria and Macro, I. (2009) Nigeria Demographic and Health Survey 2008. Key findings, Health San Francisco. Available at: http://measuredhs.com/publications/publication-sr171summary-reports-key-findings.cfm.

[52]. Ngui, R., Ishak, S., Chuen, C. and Mahmud, R. (2011) 'Prevalence and risk factors of intestinal parasitism in rural and remote West Malaysia', PLoS Negl Trop. Available at: http://journals.plos.org/plosntds/article?id=10.1371/journal.pntd.0000974 (Accessed: 22 July 2016).

[53]. Nwankwo, T., Yoon, S. S., Burt, V. and Gu, Q. (2013) 'Hypertension among adults in the United States: National Health and Nutrition Examination Survey, 2011-2012.', NCHS data brief, (133), pp. 1-8. doi: 10.1017/CBO9781107415324.004.

[54]. Ogah, O. S. (2012) 'Blood pressure, prevalence of hypertension and hypertension related complications in Nigerian Africans: A review', World Journal of Cardiology, 4(12), p. 327. doi: 10.4330/wjc.v4.i12.327.

[55]. Ogah, O. S. and Rayner, B. L. (2013) 'Recent advances in hypertension in sub-Saharan Africa.' Heart (British Cardiac Society), 99(19), pp. 1390-7. doi: 10.1136/heartjnl-2012-303227.

[56]. Önsüz, F. M. and Demir, F. (2015) 'Prevalence of hypertension and its association with obesity among school children aged 6-15 living in Sakarya province in Turkey', Turkish Journal of Medical Sciences, 45(4), pp. 907-912. doi: 10.3906/sag-1407-120.

[57]. Onwuchekwa, A. C. and Chinenye, S. (2010) 'Clinical profile of hypertension at a University Teaching Hospital in Nigeria', Vascular Health and Risk Management, 6(1), pp. 511-516. doi: 10.2147/VHRM.S10245.

[58]. Opie, L. H. and Seedat, Y. K. (2005) 'Hypertension in Sub-Saharan African populations', Circulation, 112(23), pp. 3562-3568. doi: 10.1161/CIRCULATIONAHA.105.539569.

[59]. Ortiz Marrón, H., Vaamonde Martín, R. J., Zorrilla Torrás, B., Arrieta Blanco, F., Casado López, M. and Medrano Albero, M. J. (2011) '[Prevalence, degree of control and treatment of hypertension in the adult population of madrid, Spain]', Revista Española De Salud Pública, 85(4), pp. 329-338. doi: 10.1590/S113557272011000400002

[60]. Pereira, M., Lunet, N., Azevedo, A. and Barros, H. (2009) 'Differences in prevalence, awareness, treatment and control of hypertension between developing and developed countries.' Journal of hypertension, 27(5), pp. 963-975. doi: 10.1097/HJH.0b013e3283282f65.

[61]. Picon, R. V., Fuchs, F. D., Moreira, L. B. and Fuchs, S. C. (2013) 'Prevalence of hypertension among elderly persons in urban Brazil: A systematic review with meta-analysis', American Journal of Hypertension, pp. 541548. doi: 10.1093/ajh/hps076.

[62]. Picon, R. V., Fuchs, F. D., Moreira, L. B., Riegel, G. and Fuchs, S. C. (2012) 'Trends in prevalence of hypertension in Brazil: a systematic review with meta-analysis', PLoS One, 7(10), p. e48255. doi: 10.1371/journal.pone.0048255. 
[63]. Picon, R. V., Fuchs, F. D., Moreira, L. B., Riegel, G. and Fuchs, S. C. (2012) 'Trends in Prevalence of Hypertension in Brazil: A Systematic Review with Meta-Analysis', PLoS ONE, 7(10). doi: 10.1371/journal.pone.0048255.

[64]. Ranasinghe, P., Cooray, D. N., Jayawardena, R. and Katulanda, P. (2015) 'The influence of family history of hypertension on disease prevalence and associated metabolic risk factors among Sri Lankan adults.' BMC public health, 15, p. 576. doi: 10.1186/s12889-015-1927-7.

[65]. Report, M. W. (2011) 'Vital signs: prevalence, treatment, and control of hypertension--United States, 19992002 and 2005-2008.', MMWR. Morbidity and mortality weekly report, 60(4), pp. 103-8. doi: mm6004a4 [pii]. [66]. Roberie, D. R. and Elliott, W. J. (2012) 'What is the prevalence of resistant hypertension in the United States?', Current opinion in cardiology, pp. 386-91. doi: 10.1097/HCO.0b013e328353ad6e.

[67]. Salaudeen, A. G., Musa, O. I., Babatunde, O. A., Atoyebi, O. A., Durowade, K. A. and Omokanye, L. O. (2014) 'Knowledge and prevalence of risk factors for arterial hypertension and blood pressure pattern among bankers and traffic wardens in Ilorin, Nigeria', African Health Sciences, 14(3), pp. 593-599. doi: 10.4314/ahs.v14i3.14.

[68]. Smith, A. W. (1998) 'The World Health Organisation and the prevention of deafness and hearing impairment caused by noise', Noise \& health, 1(1), pp. 6-12. Available at: http://www.ncbi.nlm.nih.gov/pubmed/12689363

[69]. Tailakh, A., Evangelista, L. S., Mentes, J. C., Pike, N. a, Phillips, L. R. and Morisky, D. E. (2014) 'Hypertension prevalence, awareness, and control in Arab countries: A systematic review.' Nursing \& health sciences, 16(1), pp. 126-30. doi: 10.1111/nhs.12060.

[70]. Thaweboon, S., Thaweboon, B., Srithavaj, T. and Choonharuangdej, S. (2008) 'Oral colonization of Candida species in patients receiving radiotherapy in the head and neck area.' Quintessence international (Berlin, Germany : 1985), 39(2), pp. e52-7. Available at: http://www.ncbi.nlm.nih.gov/pubmed/18560641

[71]. Ursua, R. A., Aguilar, D. E., Wyatt, L. C., Katigbak, C., Islam, N. S., Tandon, S. D., Nur, P. R. M. Q., Van Devanter, N., Rey, M. J. and Trinh-Shevrin, C. (2014) 'A community health worker intervention to improve management of hypertension among Filipino Americans in New York and New Jersey: A pilot study.', Ethnicity \& disease, 24(1), pp. Available 67-76. http://www.pubmedcentral.nih.gov/articlerender.fcgi?artid=3955003\&tool=pmcentrez\&rendertype=abstract [72]. van de Vijver, S. J. M., Oti, S. O., Agyemang, C., Gomez, G. B. and Kyobutungi, C. (2013) 'Prevalence, awareness, treatment and control of hypertension among slum dwellers in Nairobi, Kenya.', Journal of hypertension, 31(5), pp. 1018-24. doi: 10.1097/HJH.0b013e32835e3a56.

[73]. van de Vijver, S., Akinyi, H., Oti, S., Olajide, A., Agyemang, C., Aboderin, I. and Kyobutungi, C. (2013a) 'Status report on hypertension in Africa--consultative review for the 6th Session of the African Union Conference of Ministers of Health on NCD's.', The Pan African medical journal. doi: 10.11604/pamj.2013.16.38.3100.

[74]. van de Vijver, S., Akinyi, H., Oti, S., Olajide, A., Agyemang, C., Aboderin, I. and Kyobutungi, C. (2013b) 'Status report on hypertension in Africa--consultative review for the 6th Session of the African Union Conference of Ministers of Health on NCD's.', The Pan African medical journal, p. 38. doi: 10.11604/pamj.2013.16.38.3100. [75]. WHO (2014) 'WHO Global Tuberculosis Report 2014', WHO report, pp. 2013-2014. doi: WHO/HTM/TB/2014.08.

[76]. Yang, G., Ma, Y., Wang, S., Su, Y., Rao, W., Fu, Y., Yu, Y. and Kou, C. (2015) 'Prevalence and correlates of prehypertension and hypertension among adults in northeastern China: A cross-sectional study', International Journal of Environmental Research and Public Health, 13(1). doi: 10.3390/ijerph13010082.

[77]. Yoon, S. S. S., Carroll, M. D. and Fryar, C. D. (2015) 'Hypertension Prevalence and Control among Adults: United States, 2011-2014.', NCHS data brief, (220), pp. 1-8. Available at: http://www.ncbi.nlm.nih.gov/pubmed/26633197

[78]. Zeng, Y., Guo, L.-P., Chen, B.-D., Hao, Z.-P., Wang, J.-Y., Huang, L.-Q., Yang, G., Cui, X.-M., Yang, L., Wu, Z.-X., Chen, M.-L. and Zhang, Y. (2013) 'Arbuscular mycorrhizal symbiosis and active ingredients of medicinal plants: current research status and prospectives.', Mycorrhiza, 23(4), pp. 253-65. doi: 10.1007/s00572013-0484-0. 